\title{
Pulmonary Carbon Dioxide Elimination for Cardiac Output Monitoring in Peri-operative and Critical Care Patients: History and Current Status
}

\author{
Philip J Peyton* \\ Department of Anaesthesia, Austin Health and Department of Surgery, Austin \\ Hospital and University of Melbourne, Victoria, Australia
}

Submitted September 2012. Accepted for publication December 2012.

\begin{abstract}
Minimally invasive measurement of cardiac output as a central component of advanced haemodynamic monitoring has been increasingly recognised as a potential means of improving perioperative outcomes in patients undergoing major surgery. Methods based upon pulmonary carbon dioxide elimination are among the oldest techniques in this field, with comparable accuracy and precision to other techniques. Modern adaptations of these techniques suitable for use in the perioperative and critical are environment are based on the differential Fick approach, and include the partial carbon dioxide rebreathing method. The accuracy and precision of this approach to cardiac output measurement has been shown to be similar to other minimally invasive techniques. This paper reviews the underlying principles and evolution of the method, and future directions including recent adaptations designed to deliver continuous breath-bybreath monitoring of cardiac output.
\end{abstract}

Keywords: pulmonary blood flow, carbon dioxide, Fick principle, gas exchange

\section{INTRODUCTION}

In recent years there have been major shifts in thinking concerning optimal management of fluid resuscitation and haemodynamics in patients undergoing major surgery [1-4]. Central to this process has been the wider availability of monitors that can provide essential information to the clinician about cardiovascular status by less invasive means than those previously available, allowing their readier application for peri-operative and critical care patient management. Among the most important of these monitors are those designed to provide minimally invasive measurement of cardiac output (pulmonary blood flow). A growing number of studies and reviews have suggested that improved patient outcomes will accompany advanced haemodynamic monitoring incorporating measurement of blood flow or perfusion [5-10].

*Corresponding author: Philip John Peyton, Department of Anaesthesia, Austin Health, Studley Rd, Heidelberg 3084, VIC, Australia. Phone: +61 39496 5000, Fax: +61 39459 6421, E-mail: phil.peyton@austin.org.au. 
The invasive clinical standard for measurement of cardiac output in the perioperative and critical care setting for many years has been the pulmonary artery catheter (PAC), which allows cardiac output measurement by several means, principally by right heart thermodilution. Due to its uncertain risk-benefit profile however, the place of the PAC has become increasingly controversial and has remained largely restricted to a limited number of clinical situations: high risk cardiac surgery and management of septic shock in the intensive care unit being among the most common examples [11-13]. The development of less invasive techniques and devices promises to extend the potential benefits of advanced haemodynamic monitoring to a much wider surgical and critical care population.

A wide variety of techniques and devices for cardiac output measurement, using vastly different physical and physiological principles, have become available for perioperative and critical care applications in recent years [14]. Measurement of pulmonary blood flow from the uptake or elimination of soluble gases by the lungs is the oldest methodology for this purpose [15-17]. Methods based on carbon dioxide $\left(\mathrm{CO}_{2}\right)$ elimination by the lungs have been among the most well established of these approaches and have continued to attract interest from researchers and clinicians because of their non-invasiveness and adaptability to various clinical environments. This paper reviews this approach, its underlying principles, evolution and limitations and its performance in terms of accuracy and precision, relative to other methods for cardiac output measurement.

\section{PHYSIOLOGICAL PRINCIPLES}

\subsection{The Fick Principle}

Methods utilizing carbon dioxide $\left(\mathrm{CO}_{2}\right)$ elimination by the lungs are based on the principle of conservation of mass during lung gas exchange embodied in the classical Fick equation. Applied to $\mathrm{CO}_{2}$ elimination by the lungs, the Fick equation states

$$
\dot{Q}_{t}=\frac{\dot{V}_{\mathrm{CO}_{2}}}{C_{\mathrm{aCO}_{2}}-C_{\bar{v} \mathrm{CO}}}
$$

where $\dot{V}_{\mathrm{CO}_{2}}$ is measured volumetric flow rate of $\mathrm{CO}_{2}$ elimination (L/min), $C_{\bar{v} C O_{2}}$ and $\mathrm{C}_{a \mathrm{CO}_{2}}$ are the fractional concentrations of $\mathrm{CO}_{2}$ in mixed venous and systemic arterial blood, respectively, and $\dot{Q}_{t}$ is pulmonary volumetric blood flow rate (L/min). Direct measurement of mixed venous blood gas content is impossible without pulmonary artery catheterization, which makes the direct Fick approach impractical for routine clinical use.

Early methods used breath holding or rebreathing manoevres to estimate $C_{\bar{v} \mathrm{CO}_{2}}$ and methods for pulmonary blood flow measurement based on $\mathrm{CO}_{2}$ rebreathing continue to attract interest and innovation in the fields of exercise and sports physiology and in preoperative stress testing [18-24]. However, this approach was not readily adapted to use in the peri-operative or critical care setting. Nevertheless, pulmonary blood flow estimation based on $\mathrm{CO}_{2}$ measurement continued to attract interest. Arterial $\mathrm{CO}_{2}$ partial pressure could be approximated by measurement of end-expired $\mathrm{CO}_{2}$ partial pressure 
$\left(P_{E^{\prime} \mathrm{CO}_{2}}\right)$ and the development of capnography for routine clinical monitoring in anaesthesia made this readily accessible. Furthermore, while accurate and reproducible measurement of $\dot{V}_{\mathrm{CO}_{2}}$ on a breath-by-breath basis is technically challenging, requiring real-time integration of gas flow and concentration waveforms, it is much easier to do accurately than measurement of gas uptake, which requires measurement of gas inflow as well as outflow from the patient [25-27].

\subsection{The Differential Fick Approach}

The problem posed by the inaccessibility of mixed venous measurement was elegantly solved by the development of what has been subsequently referred to as the differential Fick approach [28]. Originally proposed by Gedeon et al., measurements of $\dot{V}_{\mathrm{CO}_{2}}$ and $P_{E^{\prime} \mathrm{CO}_{2}}$ are made at two different levels of alveolar ventilation [29]. If done prior to one recirculation time after the change in ventilation, $C_{\bar{v} \mathrm{CO}_{2}}$ can be considered to remain constant for the purposes of the measurement. Two simultaneous Fick equations are obtained, allowing for the unknown pulmonary blood flow to be solved.

To be technically correct, because the method uses $P_{E^{\prime} \mathrm{CO}_{2}}$ which is an estimate of pulmonary end-capillary (not arterial) blood, only that part of the pulmonary blood flow engaging in gas exchange, non-shunt pulmonary capillary blood flow $\dot{Q}_{c}$, is measured.

$$
\dot{Q}_{c}=\frac{\dot{V}_{C O_{2 i}}-\dot{V}_{C O_{2 j}}}{S_{\mathrm{CO}_{2}}\left(P_{E^{\prime} C O_{2 i}}-P_{E^{\prime} C O_{2 j}}\right)}
$$

where $i$ and $j$ are the two measurement points, $i$ prior to, and $j$ during the change in alveolar ventilation. $\mathrm{S}_{\mathrm{CO}_{2}}$ is the solubility coefficient of $\mathrm{CO}_{2}$ in blood, a function of the $\mathrm{CO}_{2}$ dissociation curve which requires an estimate of the patient's haemoglobin concentration and oxygen saturation $\mathrm{SpO}_{2}$ obtained from pulse oximetry [30,31].

To obtain total pulmonary blood flow, equivalent to the cardiac output $\dot{Q}_{t}$, an estimate of shunt fraction $\dot{Q}_{s} / \dot{Q}_{t}$ is required, which can be made from the $\mathrm{SpO}_{2}$ and computerized reference to published nomograms such as the "iso-shunt diagram" for example [32], so that

$$
\dot{Q}_{t}=\dot{Q}_{c} /\left(1-\dot{Q}_{s} / \dot{Q}_{t}\right)
$$

In a patient whose lungs are ventilated, the method is non-invasive. In the original study by Gedeon et al. [29] in an animal model, the change in alveolar ventilation required was made by simply changing the respiratory rate delivered by the ventilator in such a way that, by also changing the inspiratory:expiratory (I:E) ratio, the duration and pattern of inspiration was unaltered by the manoeuvre, in effect only the duration of the end-expiratory pause being increased. The authors identified this as important, because it minimized physiological sources of error with the method, by avoiding any changes in pulmonary inflation pressures or lung mechanics which might influence alveolar deadspace and the relationship between end-capillary and end-expired $\mathrm{CO}_{2}$ 

Peri-operative and Critical Care Patients: History and Current Status

partial pressures [29]. Despite encouraging agreement with an invasive standard in the form of bolus thermodilution via a pulmonary artery catheter, this precise approach was not pursued further in human studies [33]. This was possibly because of the difficulty in those days of developing an automated means of controlling a standard anaesthesia ventilator in the way needed to make the method convenient for the clinician in everyday practice.

\subsection{Partial $\mathrm{CO}_{2}$ Rebreathing}

The differential Fick approach using $\mathrm{CO}_{2}$ elimination was instead pursued using the partial rebreathing method, where a rebreathing loop of variable volume was inserted into the breathing circuit near the mouthpiece [33-35]. After obtaining baseline measurements of $\dot{V}_{\mathrm{CO}_{2}}$ and $P_{E^{\prime} \mathrm{CO}_{2}}$ the loop was opened using a valve which could be readily automated, producing a sudden increase in serial deadspace in the breathing system and a reduction in alveolar ventilation. The manoeuvre was terminated after a partial rebreathing period of 30-50 seconds when the second set of measurements of $\dot{V}_{\mathrm{CO}_{2}}$ and $P_{E^{\prime} \mathrm{CO}_{2}}$ had been captured. Figure 1 shows the acute change in these variables produced by the rebreathing manoeuvre.

Alternative approaches to the measurement of the inputs into the differential Fick equation were also reported. Parkin et al. [36,37] tested a system in ventilated patients in the intensive care unit with valve-activated diversion of inspired gas through a known volume of the expired line of the breathing circuit, with or without a fast mixing box, instead of the variable volume loop used previously. This allowed the numerator of Equation 2 to be calculated from the volume of the deadspace tubing multiplied by $P_{E^{\prime} \mathrm{CO}_{2}}$ within the tubing and the respiratory rate. This simplified approach avoided many of the technical difficulties with accurate breath-by-breath measurement of $\dot{V}_{\mathrm{CO}_{2}}$ during the rebreathing manoeuvre, with good results in terms of accuracy and precision of measurement.

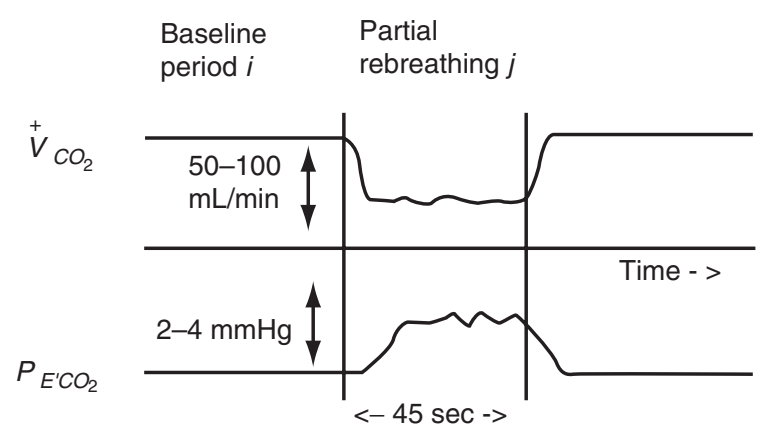

Figure 1. The partial $\mathrm{CO}_{2}$ rebreathing manoeuvre for measurement of pulmonary blood flow by the differential Fick method. Typical patterns of change are shown in $\mathrm{CO}_{2}$ elimination rate $\left(\dot{V}_{\mathrm{CO}_{2}}\right)$ and end-expired $\mathrm{CO}_{2}$ partial pressure $\left(\mathrm{P}_{E^{\prime} \mathrm{CO}_{2}}\right)$ from the baseline period $i$ and over the partial rebreathing period $j$. 
The advantage of the partial rebreathing approach was that it lent itself readily to application as a stand-alone system, with disposable single-use rebreathing loop and valve, and theoretically could be used in spontaneously breathing subject. Brought to the marketplace by Novametrix (later Respironics/Philips) it became available for clinical use in the form of the $\mathrm{NICO}^{\circledR}$ [38]. The accuracy and precision of this device has been studied in a number of publications and this technology is now becoming available as an option on the NM3 metabolic monitor (Respironics/Philips) [39-56]. These devices are shown in Figure 2.

\subsection{Back to the Future}

Over the intervening years, electronically controlled ventilators which are fully integrated into the anaesthesia delivery and monitoring system have become standard equipment in modern platforms for use in anaesthesia and critical care. This has

(a)

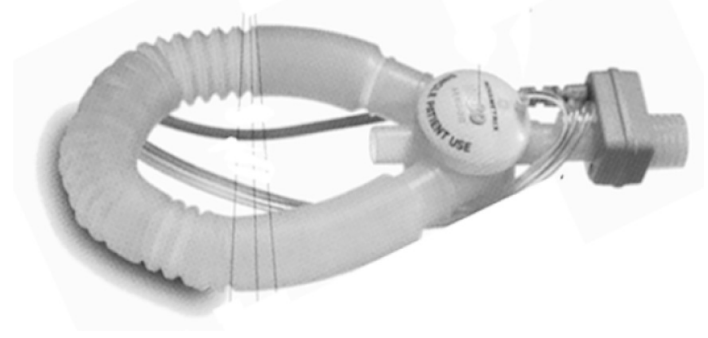

(b)

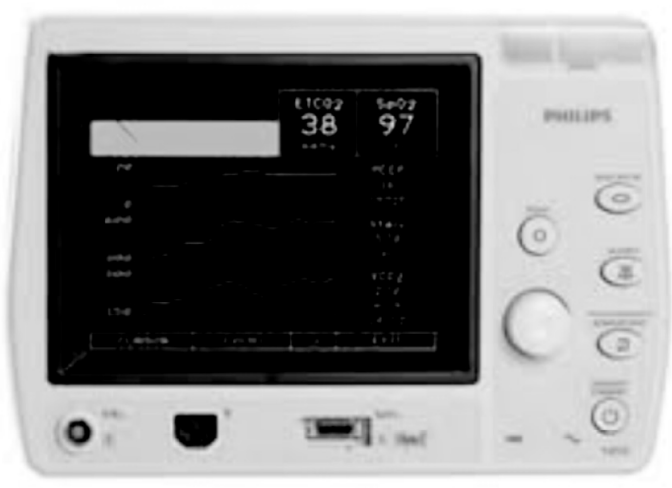

Figure 2. (a) The partial rebreathing loop developed for the Novametrix (later Respironics/Philips) NICO ${ }^{\circledR}$ monitor. (b) The Respironics/Philips NM3 metabolic monitor which incorporates the partial $\mathrm{CO}_{2}$ rebreathing cardiac output measurement capability. 

Peri-operative and Critical Care Patients: History and Current Status

raised again the potential for the original approach of Gedeon et al. [29] to provide an automated non-invasive means of delivering cardiac output measurement in ventilated patients undergoing surgery or critical care. Peyton et al. developed and tested a system employing a computer algorithm with software control of an electronic anaesthesia ventilator to obtain fully automated measurements of pulmonary blood flow [57]. They ensured that the original method of Gedeon et al. [29] was followed in which both respiratory rate $(R R)$ and I:E ratio were changed so as not to alter the duration of the inspiratory phase of the respiratory cycle or alveolar deadspace during the ventilatory maneouvre. This allowed a modified form of the differential Fick equation to be used which simplified the measurement of change in $\dot{V}_{\mathrm{CO}_{2}}$ in the numerator of the equation, by assuming no change in the relationship between $\dot{V}_{\mathrm{CO}_{2}}$ and $P_{E^{\prime} \mathrm{CO}_{2}}$ :

$$
\dot{V}_{C O_{2 i}}-\dot{V}_{C O_{2 j}}=\dot{V}_{C O_{2 i}}\left(1-\frac{P_{E^{\prime} C O_{2 j}}}{P_{E^{\prime} C O_{2 i}}} \times \frac{R R j}{R R i}\right)
$$

They tested the system in a pilot study against simultaneous measurements by bolus thermodilution in patients undergoing cardiac surgery and found similar agreement with thermodilution regardless of whether the alveolar ventilation was increased or decreased by the ventilatory manoeuvre employed [57].

This methodology was subsequently used to provide baseline and repeated calibration, performed during a brief period of stability in $\dot{V}_{\mathrm{CO}_{2}}$ and $P_{E^{\prime} \mathrm{CO}_{2}}$, for a technique for continuous monitoring of cardiac output in ventilated patients, called the Capnotracking method [58]. The relationship between cardiac output changes and $\dot{V}_{\mathrm{CO}_{2}}$ have been previously explored by Breen and Isserles using computer modeling and patient measurement $[59,60]$. In the Capnotracking algorithm, after each automated calibration, breath-by-breath monitoring of acute changes cardiac output was done using a continuity equation which assumes equal and opposite change in the numerator and denominator of Equation (1) in response to changes in $\dot{Q}_{t}$. This results in a simple relationship between change in measured $\dot{V}_{\mathrm{CO}_{2}}$ and $\dot{Q}_{t}$

$$
\dot{Q}_{t k}=\dot{Q}_{t i} \cdot\left(\frac{\dot{V}_{C O_{2 k}}}{\dot{V}_{C O_{2 i}}}\right)^{2}
$$

where $i$ is the baseline calibration measurement and $k$ is any measurement made on a subsequent breath $k$. With automated recalibration performed every 30 minutes, this was found to deliver useful real-time tracking of dramatic changes in cardiac output in both an animal model and in patients undergoing cardiac surgery or liver transplantation, and was potentially seamless and hands-free in its implementation, requiring attachment of no peripheral devices to the patient [58]. 


\section{ACCURACY AND PRECISION}

\subsection{Theoretical Analysis of Accuracy}

In a series of papers by Yem et al. some of the theoretical issues with the accuracy of the partial $\mathrm{CO}_{2}$ rebreathing method were explored using a computer model of simulated body and lung $\mathrm{CO}_{2}$ elimination [61]. They identified that systematic errors in measurement of cardiac output could arise from a number of physiological factors. These factors are summarized in Table 1 . These included recirculation of mixed venous blood prior to the termination of the rebreathing manoeuvre at high simulated cardiac outputs, and inadequate rebreathing time at low cardiac outputs due to incomplete equilibration between alveolar gas and pulmonary blood compartments. An additional factor was the presence of arterial to end-expired $\mathrm{CO}_{2}$ partial pressure differences due to the presence of significant ventilation-perfusion mismatch in the lung. This is universal in anaesthetized patients, and is the cause of the increased alveolar deadspace and pulmonary shunt that can be measured in these patients [62-64]. The common tendency of these factors was to "normalise" the calculated cardiac output, that is to overestimate low values and underestimate high values. The developers of $\mathrm{NICO}^{\circledR}$ pointed out in response that this modeling only simulated the basic theory of calculation of cardiac output, and that the algorithms employed in the device were more sophisticated than those tested in these simulations [65]. In patients with obstructive airways disease, a tendency to underestimate the cardiac output was predicted [66].

\subsection{Animal Studies}

Data from studies using animal models provide some support of the predictions of computer modeling. Haryadi et al. in dogs found good agreement of $\mathrm{NICO}^{\circledR}$ with bolus thermodilution during induced variations in haemodynamics [67]. Following earlier validation studies showing good agreement with thermodilution in a sheep model of a prototype partial $\mathrm{CO}_{2}$ rebreathing measurement system, Gama de Abreu and colleagues showed that there was a systematic tendency to normalise the cardiac output measurement, and the presence of elevated alveolar deadspace led to cardiac output underestimation $[68,69]$. They demonstrated that during high cardiac output states, the

Table 1. Physiological and pathophysiological sources of error with the partial $\mathrm{CO}_{2}$ rebreathing method and their effects on accuracy of measurement of cardiac output predicted from computer modelling. "Normalise" means to underestimate high cardiac outputs and/or overestimate low cardiac outputs $[61,66]$

\begin{tabular}{ll}
\hline Source of error & Effect on measurement \\
\hline Recirculation of mixed venous blood & Normalise high cardiac outputs \\
Inadequate rebreathing time & Normalise low cardiac outputs \\
Ventilation-perfusion mismatch & Normalise cardiac output \\
Obstructive lung disease & Underestimate cardiac output \\
Pulmonary embolism & Underestimate normal/high cardiac output
\end{tabular}


higher mixed venous $\mathrm{CO}_{2}$ partial pressures reached at the end of the rebreathing manoeuvre contributed to higher $P_{E^{\prime} \mathrm{CO}_{2}}$ and therefore to underestimation of pulmonary capillary blood flow based on Equation (2). Other work in a swine model of blunt chest trauma found a $26 \%$ underestimate of continuous thermodilution measurements in extreme laboratory conditions of trauma-induced cardiopulmonary dysfunction [70]. Comparison of $\mathrm{NICO}^{\circledR}$ measurements with bolus thermodilution in anaesthetized pigs during induced ventricular fibrillation and external chest compression showed acceptable correlation with a tendency for $\mathrm{NICO}^{\circledR}$ measurements to underestimate thermodilution but this difference declined at low cardiac outputs [71].

\subsection{Clinical Data}

The accepted statistical method for assessment of accuracy (bias) and precision (scatter) of measurement of a variable such as cardiac output is by comparison with simultaneous paired measurements made by another, accepted reference technique, as described by Bland and Altman [72]. The standard deviation of the difference between paired measurements is calculated. The average of these is the mean bias of the test method, the precision of agreement is defined as 1 standard deviation of the difference between paired measurements, and +/- 1.96 standard deviations of the difference between paired measurements are referred to as the limits of agreement with the reference method. By definition, $95 \%$ of measurements will lie between these limits. The limits of agreement divided by the mean cardiac output are commonly referred to as the percentage error.

Most published studies examining the accuracy and precision of measurement of cardiac output by a technique have used simultaneous measurements by bolus thermodilution via a PAC as the reference standard for comparison. Patients undergoing cardiac surgery or intensive care for critical illness represent a common population for these validation studies of accuracy and precision of measurement, because they have a PAC routinely placed for haemodynamic management as part of their normal clinical care.

A criterion for acceptability of precision of measurement of cardiac output by a test method was suggested by Critchley and Critchley in 1999 [73]. They stipulated that the percentage error of a method relative to thermodilution should be less than $+/-30 \%$, based on the statistical assumption that this equated to both methods being within approximately $+/-20 \%$ of the true cardiac output. Relatively few published data were available at that time to compare with this criterion. In the intervening decade the proliferation of new technologies and validation studies examining accuracy and precision has provided a great deal more data.

Peyton and Chong recently published a quantitative meta-analysis of data from 10 years of published studies comparing minimally invasive techniques for cardiac output measurement adapted to peri-operative and critical care use, where bolus thermodilution was the comparator [74,75]. Studies using continuous thermodilution were not included due to its documented poorer precision compared to bolus thermodilution in the perioperative situation [50]. They calculated a weighted average for both bias and precision for four different generic classes of technique: pulse contour techniques, oesophageal Doppler, partial $\mathrm{CO}_{2}$ rebreathing and trans-thoracic bioimpedance. They found that the percentage errors for these four approaches were similar (ranging $42-45 \%$ ), which was considerably wider than the limits of acceptability suggested by Critchley and Critchley [76]. 
In Peyton and Peyton and Chong's analysis, the bias of the partial $\mathrm{CO}_{2}$ rebreathing method, incorporating data from 8 studies, found a mean [95\% confidence intervals] bias of $-0.05[0.17] \mathrm{L} / \mathrm{min}$ with a precision of $1.12 \mathrm{~L} / \mathrm{min}$, giving a percentage error of $+/-44.5$ [6.0]\%. The pooled coefficient of correlation with thermodilution was $r=0.58$. Although data from another 7 papers were unable to be included in the pooled weighted calculation because of data quality (mainly uncontrolled inclusion of multiple measurements from subjects without statistical correction) there was no evidence from comparison of these data with the included data that there was any significant difference in the findings of the excluded studies (Figure 3) [74]. Data from these studies, obtained mostly from earlier or later software versions of $\mathrm{NICO}^{\circledR}$, included a wide variety of surgery, including one lung ventilation for thoracic surgery, and a variety of ventilatory rates and settings. Overall the performance of the method was comparable to the other generic techniques studied. These studies are listed in Table 2.

C $\mathrm{PCO}_{2} \mathrm{RB}$

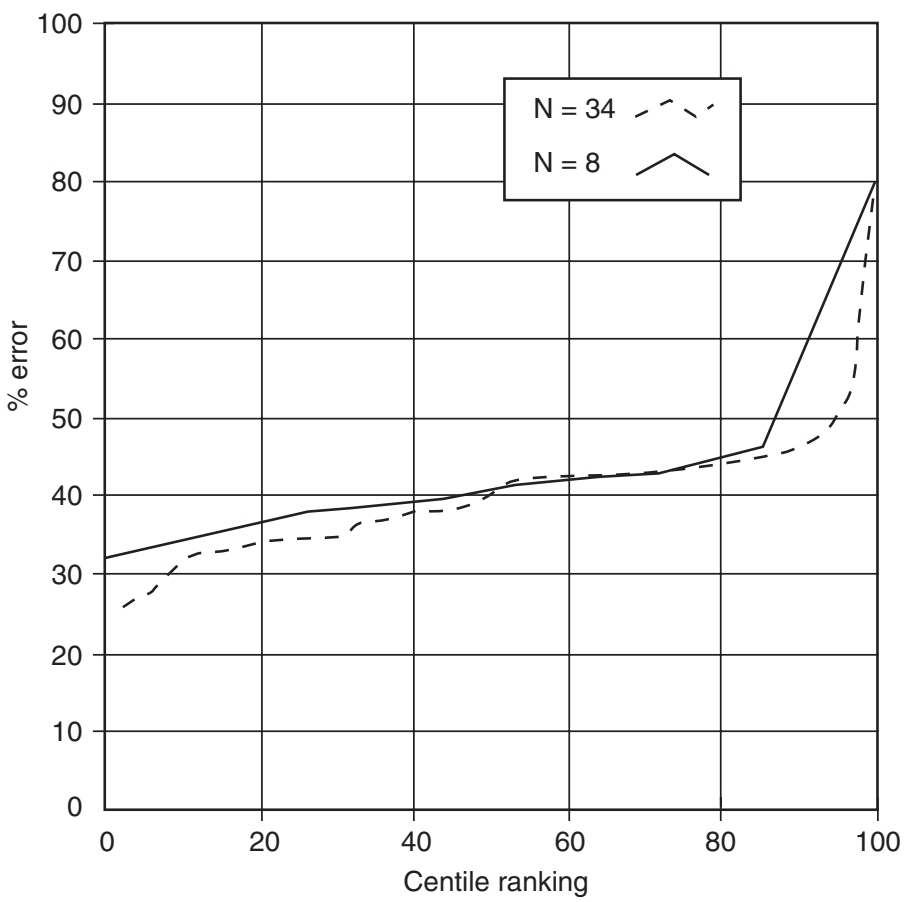

Figure 3. Distribution of percentage error in measurement of cardiac output by the partial $\mathrm{CO}_{2}$ rebreathing method $\left(\mathrm{PCO}_{2} \mathrm{RB}\right)$, among studies where comparison to thermodilution was made, from lowest (first centile) to highest (hundredth centile). The heavy line represents 8 studies where a single measurement per patient was presented, included in a pooled weighted meta-analysis. The broken line represents all sets of measurements among all studies on the method (34 studies in 15 papers). Reproduced with permission [74]. 


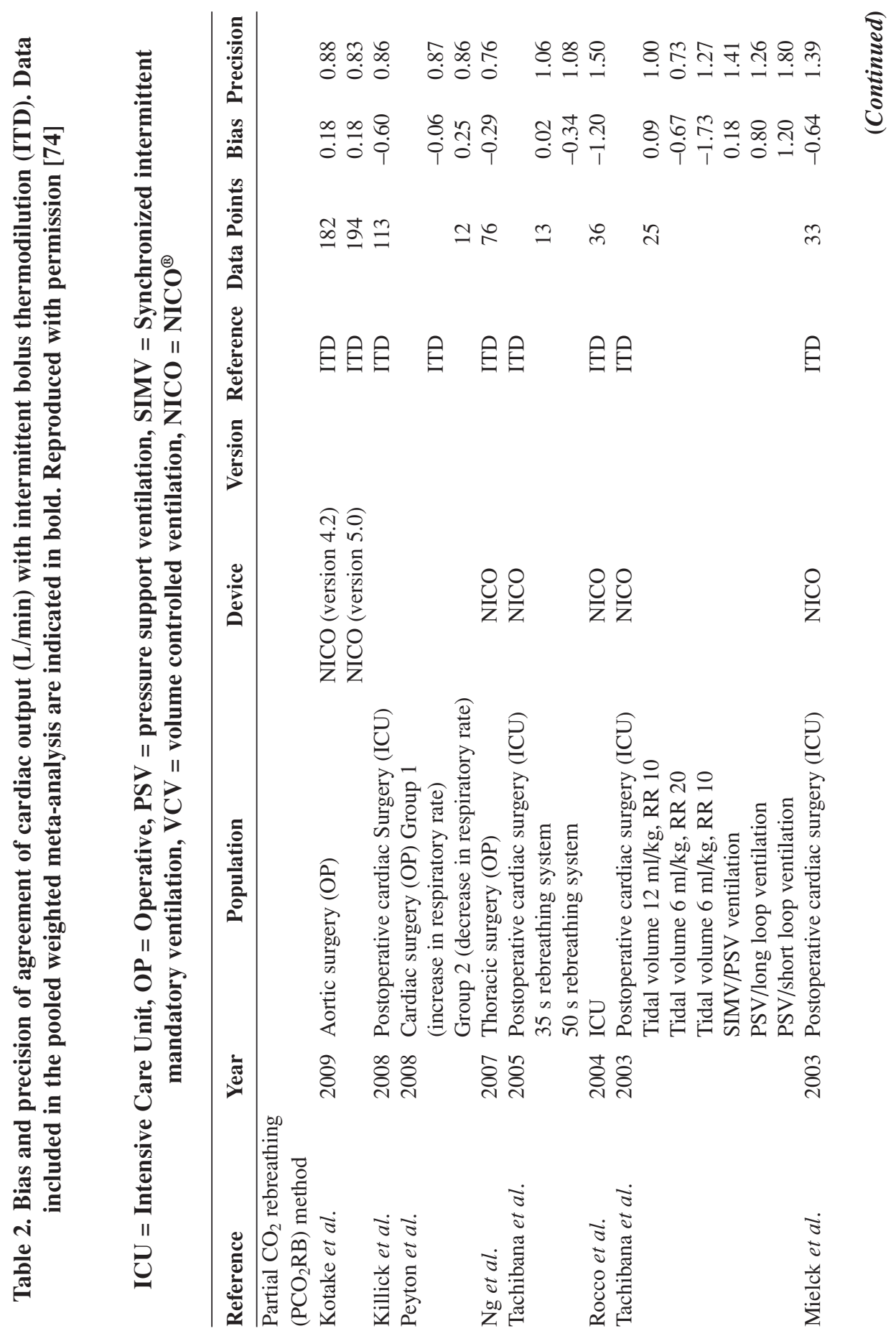




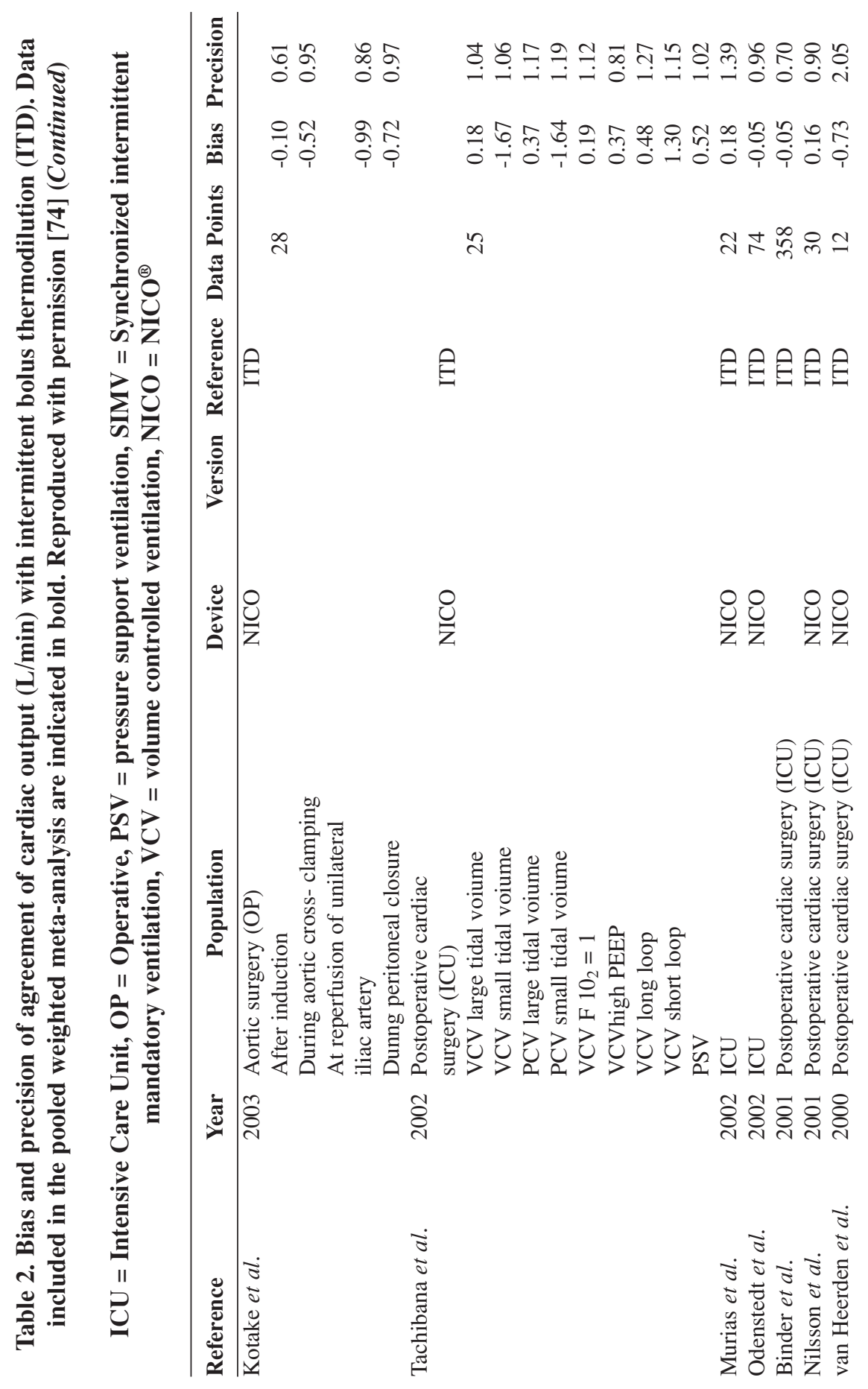


Similarly, data from a recent paper by Peyton [58] testing the Capnotracking method in comparison with bolus thermodilution in 77 patients undergoing cardiac or liver transplantation surgery found a bias of $-0.1 \mathrm{~L} / \mathrm{min}$, with a percentage error $\pm 44.2 \%$, $r=0.92$. The higher correlation arose from the very wide range of cardiac output values present in the study population $(0.7-16.4 \mathrm{~L} / \mathrm{min})$ and pointed to a high degree of linearity of response of the differential $\mathrm{CO}_{2}$ Fick approach.

However, data from other publications suggest that some of the theoretical questions about accuracy and linearity of response raised by Yem et al. have not been resolved $[61,66]$. Allardet-Servent et al. studied agreement of the partial $\mathrm{CO}_{2}$ rebreathing method in the form of the later generation $\mathrm{NICO}_{2}{ }^{\circledR}$ with continuous thermodilution in twenty patients with acute respiratory distress syndrome receiving lung protective ventilation and found a bias and percentage error of $0.8 \mathrm{~L} / \mathrm{min}$ and $36 \%$ respectively [54]. The authors attributed this error to underestimation of pulmonary shunt fraction by the $\mathrm{NICO}_{2}{ }^{\circledR}$ due to its use of a fixed value to estimate the arterio-venous $\mathrm{O}_{2}$ content difference, which is directly related to shunt fraction in standard concepts of ventilation-perfusion maldistribution in the lung. They found a much closer agreement in measurement of non-shunt pulmonary capillary blood flow (using total pulmonary blood flow obtained from thermodilution corrected for measured shunt fraction as the reference) which was consistent with this assumption. Subsequent improvements in the algorithm incorporating reference to the iso-shunt diagram instead may improve this source of bias [32].

Earlier investigation of the partial $\mathrm{CO}_{2}$ rebreathing method by Gama de Abreu et al. suggested that precision and reproducibility of measurement of cardiac output was significantly poorer in patients who were not undergoing controlled mechanical ventilation [77]. Data from the small number of patients in whom it has been tested during spontaneous ventilation with pressure support are not encouraging, with bias ranging from 0.18 to $1.2 \mathrm{~L} / \mathrm{min}$, and precision (standard deviation $1.26-1.8 \mathrm{~L} / \mathrm{min}$ ) which is toward the upper end of the range seen among minimally invasive methods for perioperative cardiac output measurement $[43,45,74,77]$. Tachibana and colleagues have investigated $\mathrm{NICO}^{\circledR}$ extensively in various modes of ventilation (pressure controlled, volume controlled and pressure support modes) with a specific focus on the effect of these on accuracy of measurement. They demonstrated that variations in the length of the rebreathing loop and extremes of tidal volume and rate selection could elicit significant changes in bias within a given patient group [43,45]. Linearity of agreement with thermodilution was best when the tidal volume was set at relatively higher levels $(12 \mathrm{~mL} / \mathrm{kg})$ with minute ventilation maintained at a sufficient level to achieve mild arterial hypocapnia.

Some commentators recommend that relatively low tidal volumes with accompanying higher respiratory rates, in accordance with a "lung protective" ventilation strategy, may be associated with improved postoperative lung function [78]. For this reason validation of the Capnotracking method was performed using baseline ventilation settings with a lower tidal volume and higher respiratory rate [58]. The most significant biases with $\mathrm{NICO}^{\circledR}$ measured in the studies listed in Table 2 were seen in the presence of hypercapnia, due to low tidal volume, rate or a combination of them, 
regardless of mode of ventilation. Its accuracy in one lung ventilation for thoracic surgery is open to question, because of the substantial changes in ventilation-perfusion relationships in the lung that occur. However, a study by $\mathrm{Ng}$ et al. using the $\mathrm{NICO}^{\circledR}$ found relatively good preservation of accuracy with the change from two lung to one lung ventilation, with the biggest increase in bias seen early after the change and subsequently reducing $[40,79]$.

Peyton et al. have reported that the differential Fick $\mathrm{CO}_{2}$ method based on the original method of Gedeon et al. [29] employed in their studies does not work reliably in that small proportion of patients with severe obstructive lung disease with chronic gas trapping [58]. This is because an increase in duration of the end-expiratory pause that accompanies the drop in respiratory rate may partly improve effective alveolar ventilation, particularly to lung regions with moderately low ventilation/perfusion ratios, where most pulmonary gas exchange takes place. This may paradoxically increase rather than decrease $\mathrm{CO}_{2}$ clearance, or at least render the manoeuvre ineffective for measurement purposes. The partial rebreathing method using a rebreathing loop is more advantageous in this situation because the pattern of ventilatory mechanics does not change during the rebreathing manaoeuvre. Gama de Abreu et al. found well preserved agreement with thermodilution in patients with acute lung injury using a partial rebreathing system [80]. The accuracy of $\mathrm{NICO}^{\circledR}$ is adversely affected by use of Xenon in the gas mixture, due to Xenon's different density and viscosity and their influence on the accuracy of gas flow rates by the device's pneumotachograph [55].

\section{DISCUSSION}

\subsection{Limitations and Advantages}

While effectively non-invasive in patients who are intubated and ventilated, the use of the differential Fick $\mathrm{CO}_{2}$ approach to cardiac output monitoring is largely restricted to this patient population. For instance, patients undergoing major lower limb surgery under neuraxial block require an alternative method for cardiac output monitoring. This also makes it less adaptable than some other devices for transition of the postoperative patient to the high-dependency care unit, where ongoing advanced cardiovascular monitoring and goal directed haemodynamic management may be required. Other limitations of the partial $\mathrm{CO}_{2}$ rebreathing method include the requirement for incorporation of the rebreathing loop into the breathing system near the patient's airway. This can be somewhat cumbersome and impractical in some situations, for example, during head and neck surgery.

When assessing these mixed results from a variety of clinical situations, it may be concluded that techniques based on lung gas exchange for the measurement of cardiac output are not an ideal choice in patients with severe lung disease, and methods based on pulmonary $\mathrm{CO}_{2}$ elimination share the same limitation. This is because of the various sources of error that may accompany the measurement in this patient population. The variability in accuracy in different modes of ventilation documented in the studies quoted earlier makes its reliability during weaning from ventilatory support in critical care unproven. It should be pointed out, though, that there are relatively few published 
validation data for the accuracy and precision of any of the generic methods for cardiac output monitoring in the non-ventilated patient, with most data being gathered in patients undergoing elective cardiac surgery due to the ready availability of measurements from the PAC in this group.

The usefulness of the differential Fick $\mathrm{CO}_{2}$ approach in various other clinical situations requires examination. Formal validation of its accuracy and precision in the setting of laparoscopic surgery is also warranted, because of the significant changes in pulmonary $\mathrm{CO}_{2}$ elimination that accompany its absorption from the peritoneal cavity. Despite encouraging data from case reports of its successful use in guiding haemodynamic management in laparoscopic surgery in the presence of substantial cardiovascular instability, formal comparison studies with reference standards such as thermodilution are still lacking in this surgical setting [81-83]. It has received US FDA approval for use with tidal volumes of more than $200 \mathrm{~mL}$, but has been tested in a paediatric population in only one study by Levy et al. [56]. These authors found accuracy and precision of agreement with thermodilution which they deemed clinically acceptable in children with body surface area over $0.6 \mathrm{~m}^{2}$ and where tidal volume was set at more than $300 \mathrm{~mL}$.

The advantages of the differential Fick $\mathrm{CO}_{2}$ method are firstly that it is effectively non-invasive in patients who are intubated and ventilated for surgery or critical care. In addition this technology provides continuous data on the patient's metabolic status, with ongoing capnography and monitoring of $\dot{V}_{\mathrm{CO}_{2}}$, which is useful to inform nutritional and metabolic management in a septic or critically ill patient. The $\mathrm{NICO}^{\circledR}$ and NM3 monitors also provide measurements of pulmonary deadspace, functional residual capacity, and airway compliance and resistance. The methodology described by Gedeon et al. [29] and pursued by Peyton et al. [57,58], with automated modulation of respiratory rate and I:E ratio delivered by the ventilator, avoids additional peripheral equipment and can potentially be fully integrated into the anaesthesia delivery and monitoring platform.

Another advantage of methods based on lung $\mathrm{CO}_{2}$ elimination may be their relative robustness in the face of sudden cardiovascular collapse. The animal study by Carretero and various case reports have demonstrated that $\mathrm{NICO}^{\circledR}$ delivers cardiac output measurements in ventilated subjects even in the presence of vigorous chest compressions and extreme haemodynamic instability which might present large technical challenges to measurement of input variables for the method [71]. These case reports show that many of the alternative devices available for continuous cardiac output monitoring have more prolonged response times than the $\mathrm{NICO}^{\circledR}$ or fail to provide a meaningful measurement at all during profound circulatory collapse $[84,85]$. A number of authors have investigated the utility of $\mathrm{CO}_{2}$ elimination, in the form of $P_{E^{\prime} \mathrm{CO}_{2}}$ measurement, as in index of pulmonary blood flow during cardiopulmonary resuscitation [86-88]. Peyton [58] and Peyton et al. [98] demonstrated the ability of measured $\mathrm{CO}_{2}$ elimination to successfully follow dramatic changes in pulmonary blood flow in real time in both an animal model and in patients undergoing major surgery, including episodes of cardiac arrest, and during run onto cardiopulmonary bypass. 


\subsection{Assessment of Techniques for Cardiac Output Monitoring}

Arguably the theoretical critique made by Yem et al. on the accuracy of the partial $\mathrm{CO}_{2}$ rebreathing method was the result of the transparency of the method, and its clear physiological basis, which opens it to detailed scrutiny $[61,66]$. This should not be seen as a weakness, and it stands in contrast to some other technologies in the cardiac output measurement field, and other areas of patient monitoring. In a 2005 editorial, Ruskin and Shelley pointed out the potential pitfalls and dangers that accompany the trend toward adoption of new monitoring technologies with complex "black box" algorithms [90]. These authors referred to this phenomenon as "patent medicine". Ironically, however, publication under patent protection arguably presents a lesser obstacle to transparency than the intellectual property strategy based upon keeping these algorithms the proprietary secrets of their developers. Other commentators have spoken on the need for rigor in the regulatory framework for approval and licensing of new patient monitoring modalities, and the tension between this and the "black box" approach reinforces the need for thorough clinical testing of new devices and technologies, preferably with large clinical trials conducted independently of commercial support from developers [90,91].

There has been an explosion of interest in improved haemodynamic monitoring in the last decade, driven synergistically by suggestions that traditional approaches to maintenance of cardiovascular stability, such as liberal fluid maintenance and resuscitation strategies may be detrimental to patient outcomes. Indeed this has led some authorities to recommend that use of certain cardiac output monitoring devices as part of a "goal directed" management strategy should be made a standard of care in major surgery $[92,93]$. This has been criticized over the lack of data confirming these outcome benefits from large multicentre studies, despite expressions of support by many practitioners [94-97]. Such large studies should be a research priority so that any potential for advanced haemodynamic monitoring, including minimally invasive cardiac output monitors, to improve patient outcomes in routine practice can be confirmed.

\section{CONCLUSION}

Minimally invasive measurement of cardiac output as a central component of advanced haemodynamic monitoring has been increasingly recognised as a potential means of improving perioperative outcomes in patients undergoing major surgery. Techniques for monitoring of cardiac output based on lung gas exchange have a long pedigree in the field, and methods based on pulmonary $\mathrm{CO}_{2}$ elimination are well adapted to use in ventilated patients with a track record of accuracy and precision equal to other devices suitable for peri-operative and critical care use. In the midst of the recent proliferation of devices and alternative techniques for cardiac output measurement, the $\mathrm{CO}_{2}$ based approach warrants assessment in larger effectiveness trials to determine its ability to benefit patient management and outcomes in the perioperative and critical care setting. 

Peri-operative and Critical Care Patients: History and Current Status

\section{CONFLICT OF INTEREST}

Philip Peyton is the inventor on a United States Patent Application No. 12/743224, 2010 in the name of Philip John Peyton, entitled: "System and method for monitoring cardiac output".

\section{REFERENCES}

[1] Donati A, Loggi S, Preiser JC, Orsetti G, Munch C, Gabbanelli V, Pelaia P, Pietropaoli P. Goal-directed introperative therapy reduces morbidity and length of hospital stay in high-risk surgical patients. Chest, 2007, 132(6):1817-24.

[2] Bundgaard-Nielsen M, Holte K, Secher NH, Kehlet H. Monitoring of peri-operative fluid administration by individualized goal-directed therapy. Acta Anaesthesiol Scand 2007, 51: 331-340.

[3] Chappell D, Jacob M, Hofmann-Kiefer K, Conzen P, Rehm M. A Rational Approach to Perioperative Fluid management. Anesthesiology, 2008, 109(4): 723-40.

[4] Rahbari NN, Zimmermann JB, Schmidt T, Koch M, Weigand MA, Weitz J. Meta-analysis of standard, restrictive and supplemental fluid administration in colorectal surgery. British Journal of Surgery, 2009, 96: 331-41.

[5] Chytra I, Pradl R, Bosman R, Pelnár̆; P, Kasal E, Židková A. Esophageal Doppler-guided fluid management decreases blood lactate levels in multiple-trauma patients: a randomized controlled trial. Critical Care, 2007, 11:R24.

[6] Abbas SM, Hill AG. Systematic review of the literature for the use of oesophageal Doppler monitor for fluid replacement in major abdominal surgery. Anaesthesia, 2008, 63: 44-51.

[7] Roche AM, Miller TE, Gan TJ. Goal-directed fluid management with trans-oesophageal Doppler. Best Practice \& Research Clinical Anaesthesiology. 2009, 23: 327-334.

[8] Gurgel ST, do Nascimento P. Maintaining Tissue Perfusion in High-Risk Surgical Patients: A Systematic Review of Randomized Clinical Trials. Anesth Analg, 2011,112:1384-91.

[9] Hamilton MA, Cecconi M, Rhodes A. A systematic review and meta-analysis on the use of preemptive hemodynamic intervention to improve postoperative outcomes in moderate- and high-risk surgical patients. Anesth Analg 2011, 112:1392-402.

[10] Corcoran T, Rhodes JE, Clarke S, Myles PS, Ho KM. Perioperative fluid management strategies in major surgery: a stratified meta-analysis. Anesth Analg. 2012,114(3): 640-51.

[11] Connors AF Jr, Speroff T, Dawson NV, Thomas C, Harrell FE Jr, Wagner D, Desbiens N, Goldman L, Wu AW, Califf RM, Fulkerson WJ Jr, Vidaillet H, Broste S, Bellamy P, Lynn J, Knaus WA. The effectiveness of right heart catheterization in the initial care of critically ill patients. SUPPORT Investigators. JAMA, 1996, 18,276(11):889-97.

[12] Wiener RS, Welch HG. Trends in the use of the pulmonary artery catheter in the United States, 1993-2004. JAMA. 2007, Jul 25,298(4): 423-9.

[13] Cowie BS. Does the pulmonary artery catheter still have a role in the perioperative period? Anaesth Intensive Care, 2011, 39: 345-355.

[14] Funk DJ, Moretti EW, Gan TJ. Minimally Invasive Cardiac Output Monitoring in the Perioperative Setting. Anesth Analg, 2009,108: 887-97.

[15] Fick A. Uber die messung des Blutquantums in den Hertzventrikeln. Sitzber Physik Med Ges, Wurzburg July 9th: 36, 1870.

[16] Krogh A and Lindhard J. Measurements of the blood flow through the lungs of man. Scand Arch Physiol, 1912, 27: 100-125.

[17] Laszlo G. Respiratory measurements of cardiac output: from elegant idea to useful test. J Appl Physiol, 2004, 96: 428-437. 
[18] Kim TS, Rahn H, Farhi LE: Estimation of true venous and arterial $\mathrm{PCO}_{2}$ by gas analysis of a single breath. J Appl Physiol, 1966, 21:1338-1344.

[19] Collier C: Determination of mixed venous $\mathrm{CO}_{2}$ tensions by rebreathing. J Appl Physiol, 1956, 9:25-29

[20] Defares JG. Determination of $\mathrm{PvCO}_{2}$ From the exponential $\mathrm{CO}_{2}$ Rise During Rebreathing. J Appl Physiol, 1958, 13(2): 159-64.

[21] Espersen K, Jensen EW, Rosenborg D, Thomsen JK, Eliasen K, 1sen NV, Kanstrup I-L. Comparison of cardiac output measurement techniques: thermodilution, Doppler, $\mathrm{CO}_{2}$-rebreathing and direct Fick method. Acta Anaesthesiol Scand 1995, 39: 245-51.

[22] Olszowka AJ, Shykoff BE, Pendergast DR, Lundgren CE, Farhi LE. Cardiac output: a view from Buffalo. Eur J Appl Physiol, 2003 Oct,90(3-4):292-304.

[23] Olszowka AJ, Shykoff BE, Pendergast DR, Farhi LE. Revised one-step method for determination of cardiac output. Respir Physiol Neurobiol, 2004, 140(1):99-109.

[24] Cade WT, Nabar SR, Keyser RE. Reproducibility of the exponential rise technique of $\mathrm{CO}_{2}$ rebreathing for measuring $\mathrm{PvCO}_{2}$ and $\mathrm{CvCO}_{2}$ to non-invasively estimate cardiac output during incremental, maximal treadmill exercise. Eur J Appl Physiol, 2004,91(5-6):669-76.

[25] Noguchi H, Ogushi Y, Yoshiya I, Itakura N, Yamabayashi H. Breath-by-breath and require compensation for transport delay and dynamic response. J Appl Physiol Respirat Environ. Exercise Physiol, 1981, 51(6): 1662-75.

[26] Beaver W, Lamarra N, Wasserman K. Breath-by-breath measurement of true alveolar gas exchange. $J$ Appl Physiol Respirat Environ. Exercise Physiol, 1979, 46(6): 1122-6.

[27] Wessel HU, Stout RL, Bastanier CK and Paul MH. Breath-by breath variation of FRC: effect on $\mathrm{VO}_{2}$ and $\mathrm{VCO}_{2}$ measured at the mouth. $J$ Appl Physiol Respirat Environ. Exercise Physiol, 1979, 46(6): $1122-6$.

[28] Capek JM and Roy RJ. Noninvasive Measurement of Cardiac Output During Partial $\mathrm{CO}_{2}$ Rebreathing. IEEE Transactions on Biomedical Engineering, 1988, 35: 653-61.

[29] Gedeon A, Forslund L, Hedenstierna G, Romano E. A new method for noninvasive bedside determination of pulmonary blood flow. Med Biol Eng Comput, 1980, 18: 411-18

[30] Kelman GR. Digital computer subroutine for the conversion of oxygen tension into saturation. J Appl Physiol, 1966, 21(4): 1375-1376.

[31] Kelman GR. Digital computer procedure for the conversion of $\mathrm{PCO}_{2}$ into blood $\mathrm{CO}_{2}$ content. Respir Physiol, 1967, 3: 111-115.

[32] Nunn J. Nunn's Applied Respiratory Physiology, 4th Ed, Butterworth-Heinemann, 1993, 183-4.

[33] Bosman RJ, Stountenbeek CP, Zandstra DF. Non-invasive pulmonary blood flow measurement by means of $\mathrm{CO}_{2}$ analysis of expiratory gases. Intensive Care Med, 1991, 17: 98-102.

[34] Blomqvist H, Frostell C, Hedenstierna G. A non-invasive technique for measurement of lung perfusion, Intensive Care Med, 1986, 12: 172-8.

[35] Capek J, Roy R. Encyclopedia of Medical Devices and Instrumentation. J.G. Webster (ed). Wiley, N.Y. 1988, 1309-10.

[36] Binder J, Parkin W. Non-Invasive Cardiac Output Determination: Comparison of a New PartialRebreathing Technique with Thermodilution. Anaesth Intensive Care. 2001, 29: 19-23.

[37] Killick CJ, Parkin WG: Non-invasive cardiac output measurement using a fast mixing box to measure carbon dioxide elimination. Anaesth Intensive Care 2008, 36: 665-73

[38] Jaffe MB. Partial $\mathrm{CO}_{2}$ rebreathing cardiac output—operating principles of the NICO system. J Clin Monit Comput, 1999, 15: 387-401

[39] Kotake Y, Yamada T, Nagata H, Suzuki T, Serita R, Katori N, Takeda J, Shimizu H: Improved accuracy of cardiac output estimation by the partial $\mathrm{CO}_{2}$ rebreathing method. J Clin Monit Comput, 2009, 23: 149-55 
[40] Ng JM, Chow MY, Ip-Yam PC, Goh MH, Agasthian T: Evaluation of partial carbon dioxide rebreathing cardiac output measurement during thoracic surgery. J Cardiothorac Vasc Anesth, 2007, 21: 655-8.

[41] Tachibana K, Imanaka H, Takeuchi M, Nishida T, Takauchi Y, Nishimura M: Effects of reduced rebreathing time, in spontaneously breathing patients, on respiratory effort and accuracy in cardiac output measurement when using a partial carbon dioxide rebreathing technique: A prospective observational study. Crit Care, 2005, 9: R569-74.

[42] Rocco M, Spadetta G, Morelli A, Dell'Utri D, Porzi P, Conti G, Pietropaoli P: A comparative evaluation of thermodilution and partial $\mathrm{CO}_{2}$ rebreathing techniques for cardiac output assessment in critically ill patients during assisted ventilation. Intensive Care Med, 2004, 30: 82-7.

[43] Tachibana K, Imanaka H, Takeuchi M, Takauchi Y, Miyano H, Nishimura M: Noninvasive cardiac output measurement using partial carbon dioxide rebreathing is less accurate at settings of reduced minute ventilation and when spontaneous breathing is present. Anesthesiology, 2003, 98: 830-7.

[44] Kotake Y, Moriyama K, Innami Y, Shimizu H, Ueda T, Morisaki H, Takeda J: Performance of noninvasive partial $\mathrm{CO}_{2}$ rebreathing cardiac output and continuous thermodilution cardiac output in patients undergoing aortic reconstruction surgery. Anesthesiology, 2003, 99: 283-8.

[45] Tachibana K, Imanaka H, Miyano H, Takeuchi M, Kumon K, Nishimura M: Effect of ventilatory settings on accuracy of cardiac output measurement using partial $\mathrm{CO}_{2}$ rebreathing. Anesthesiology, 2002, 96: 96-102.

[46] Murias GE, Villagra A, Vatua S, del Mar Fernandez M, Solar H, Ochagavia A, Fernandez R, Lopez Aguilar J, Romero PV, Blanch L: Evaluation of a noninvasive method for cardiac output measurement in critical care patients. Intensive Care Med, 2002, 28: 1470-4.

[47] Odenstedt $\mathrm{H}$, Stenqvist O, Lundin S: Clinical evaluation of a partial $\mathrm{CO}_{2}$ rebreathing technique for cardiac output monitoring in critically ill patients. Acta Anaesthesiol Scand, 2002, 46: 152-9.

[48] Nilsson LB, Eldrup N, Berthelsen PG: Lack of agreement between thermodilution and carbon dioxiderebreathing cardiac output. Acta Anaesthesiol Scand, 2001, 45: 680-5.

[49] van Heerden PV, Baker S, Lim SI, Weidman C, Bulsara M: Clinical evaluation of the non-invasive cardiac output (NICO) monitor in the intensive care unit. Anaesth Intensive Care, 2000, 28: 427-30.

[50] Botero M, Kirby D, Lobato EB, Staples ED, Gravenstein N: Measurement of cardiac output before and after cardiopulmonary bypass: Comparison among aortic transit-time ultrasound, thermodilution, and noninvasive partial $\mathrm{CO}_{2}$ rebreathing. J Cardiothorac Vasc Anesth, 2004, 18: 563-72.

[51] Gueret G, Kiss G, Rossignol B, Bezon E, Wargnier JP, Miossec A, Corre O, Arvieux CC. Cardiac output measurements in off-pump coronary surgery: comparison between NICO and the Swan-Ganz catheter. Eur J Anaesthesiol,. 2006, 23(10): 848-54.

[52] Gueret G, Kiss G, Khaldi S, Le Jouan R, Le Grand A, Perrament Y, Lefèvre C, Arvieux CC. Comparison of cardiac output measurements between NICO and the pulmonary artery catheter during repeat surgery for total hip replacement. Eur J Anaesthesiol, 2007, 24(12): 1028-33.

[53] Jover JL, Soro M, Belda FJ, Aguilar G, Caro P, Ferrandis R. [Measurement of cardiac output after cardiac surgery: validation of a partial carbon dioxide rebreathing (NICO) system in comparison with continuous thermodilution with a pulmonary artery catheter]. Rev Esp Anestesiol Reanim, 2005, 52(5): 256-62.

[54] Allardet-Servent J, Forel JM, Roch A, Chiche L, Guervilly C, Bouzana F, Vincent A, Gainnier M, Loundou A, Papazian L. Pulmonary capillary blood flow and cardiac output measurement by partial carbon dioxide rebreathing in patients with acute respiratory distress syndrome receiving lung protective ventilation. Anesthesiology, 2009, 111(5): 1085-92.

[55] Bein B, Hanne P, Hanss R et al. Effect of xenon anaesthesia on accuracy of cardiac output measurement using partial $\mathrm{CO}_{2}$ rebreathing. Anaesthesia, 2004, 59: 1104-1110.

[56] Levy RJ, Chiavacci RM, Nicolson SC, Rome JJ, Lin RJ, Helfaer MA, Nadkarni VM. An evaluation of a noninvasive cardiac output measurement using partial carbon dioxide rebreathing in children. Anesth Analg. 2004, 99(6): 1642-7 
[57] Peyton P, Thompson D, Junor P. Non-invasive automated measurement of cardiac output during stable cardiac surgery using a fully integrated differential $\mathrm{CO}_{2}$ Fick method. J Clin Monit Comput, 2008 Aug, 22(4): 285-92.

[58] Peyton P. Continuous Minimally Invasive Peri-operative Monitoring of Cardiac Output by Pulmonary Capnotracking: Comparison with Thermodilution and Transesophageal Echocardiography. J Clin Monit Comput, 2012, 26 (2): 121-32.

[59] Isserles SA, Breen PH. Can Changes in End-Tidal $\mathrm{PCO}_{2}$ Measure Changes in Cardiac Output? Anesth Analg, 1991, 73: 808-14.

[60] Breen PH. How do changes in exhaled $\mathrm{CO}_{2}$ measure changes in cardiac output? A numerical analysis model. J Clin Monit Comput, 2010, 24: 413-9.

[61] Yem J, Tang Y, Turner MJ, Baker AB. Sources of error in non-invasive pulmonary blood flow measurements by partial re-breathing: a computer study. Anesthesiology, 2003, 98: 881-7.

[62] Lundh R, Hedenstierna G: Ventilation-Perfusion Relationships during Anesthesia and Abdominal Surgery. Acta Anaesth Scand, 1983, 27: 167-73.

[63] Hedenstierna G, Lundh R, Johansson H: Alveolar Stability during Anesthesia for Reconstructive Vascular Surgery in the Leg. Acta Anaesth. Scand, 1983, 27: 26-34.

[64] Rehder K, Knopp TJ, Sessler AD, Didier EP. Ventilation-perfusion relationship in young healthy awake and anesthetized-paralyzed man. J Appl Physiol: Respirat Environ Exercise Physiol, 1979, 47(4): 745-53.

[65] Orr JA, Kück K, Brewer LM. Noninvasive Cardiac Output Monitor Algorithms Are More Sophisticated and Perform Better than Indicated in Modeling Paper. Anesthesiology, 2003, 99:1461-2.

[66] Yem JS, Turner MJ, Baker AB. Sources of error in partial rebreathing pulmonary blood flow measurements in lungs with emphysema and pulmonary embolism. British Journal of Anaesthesia, 2006, 97 (5): 732-41.

[67] Haryadi DG, Orr JA, Kueck K, McJames S, Westenskow DR. Partial $\mathrm{CO}_{2}$ rebreathing indirect Fick technique for noninvasive measurement of cardiac output. J Clin Monit Comput, 2000, 16: 361-74.

[68] Gama de Abreu M, Quintel M, Ragaller M, etal: Partial carbon dioxide rebreathing: A reliable technique for noninvasive measurement of nonshunted pulmonary capillary blood flow. Crit Care Med, 1997, 25:675-83.

[69] Gama de Abreu M, Winkler T, Pahlitzsch T, Weismann D, Albrecht DM: Performance of the partial $\mathrm{CO}_{2}$ rebreathing technique under different hemodynamic and ventilation/perfusion matching conditions. Crit Care Med, 2003, 31: 543-51.

[70] Maxwell RA, Gibson JB, Slade JB, Fabian TC, Proctor KG. Noninvasive cardiac output by partial $\mathrm{CO}_{2}$ rebreathing after severe chest trauma. J Trauma, 2001,51(5): 849-53.

[71] Carretero MJ, Fontanals J, Agustí M, Arguis MJ, Martínez-Ocón J, Ruiz A, Rios J. Monitoring in resuscitation: comparison of cardiac output measurement between pulmonary artery catheter and NICO. Resuscitation, 2010, 81(4): 404-9.

[72] Bland JM, Altman DG. Statistical methods for assessing agreement between two methods of clinical measurement. Lancet, 1986, 307-10.

[73] Critchley LAH, Critchley JA: A Meta-Analysis of Studies Using Bias and Precision Statistics to Compare Cardiac Output Measurement Techniques. J Clin Monit Comput, 1999, 15: 85-91.

[74] Peyton P, Chong SW. Minimally invasive measurement of cardiac output during surgery and critical care: A meta-analysis of accuracy and precision. Anesthesiology, 2010, 113 (5): 1220-35.

[75] Peyton P, Chong SW. Minimally Invasive Measurement of Cardiac Output During Surgery and Critical Care: A Meta-analysis of Accuracy and Precision: Erratum. Anesthesiology, 2012, 116: 972-3.

[76] Critchley AH, Peyton PJ, Chong SW. Bias and Precision Statistics: Should We Still Adhere to the 30\% Benchmark for Cardiac Output Monitor Validation Studies? Anesthesiology, 2011, 114:1245-6.

[77] Gama de Abreu M, Melo MFV, Giannella Neto A: Pulmonary capillary blood flow by partial $\mathrm{CO}_{2}$ rebreathing: Importance of the regularity of the respiratory pattern. Clin Physiol, 2000, 5:388-398. 
[78] Perioperative lung protection strategies in cardiothoracic anesthesia: are they useful? Slinger P, Kilpatrick B. Anesthesiol Clin, 2012 Dec,30(4): 607-28.

[79] Fujii S, Kikura M, Takada T, Katoh S, Aoyama N, Sato S. A noninvasive partial carbon dioxide rebreathing technique for measurement of pulmonary capillary blood flow is also a useful oxygenation monitor during one-lung ventilation. J Clin Anesth, 2004,16: 347-352.

[80] de Abreu MG, Geiger S, Winkler T, Ragaller M, Pfeiffer T, Leutheuser D, Albrecht DM. Evaluation of a new device for noninvasive measurement of nonshunted pulmonary capillary blood flow in patients with acute lung injury. Intensive Care Med, 2002, 28(3): 318-23.

[81] Suzuki M, Koda S, Nakamura Y, Kawamura N, Shimada Y. The relationship between cardiac output measured by the thermodilution method and that measured by the carbon dioxide rebreathing technique during laparoscopic surgery. Anesth Analg, 2005, 100(5): 1381-3.

[82] $\mathrm{Ng} \mathrm{JM}$. The partial $\mathrm{CO}_{2}$ rebreathing cardiac output measurement during laparoscopic resection of bilateral pheochromocytoma. Anesth Analg, 2006,103(6): 1600-1.

[83] Hong JY. Haemodynamic and ventilatory effects of preoperative epidural analgesia during laparoscopic hysterectomy using NICO. Singapore Med J, 2008, 49(3): 233-8.

[84] Vannucci A, Krejci V, Kangrga I. Performance of Vigileo and LiDCOplus cardiac output monitors during a prolonged cardiac arrest and resuscitation. Eur J Anaesthesiol, 2009, 26: 885-7.

[85] Nishiwaki C, Kotake Y, Yamada T, Nagata H, Tagawa M, Takeda J. Response Time of Different Methods of Cardiac Output Monitoring During Cardiopulmonary Resuscitation and Recovery. $J$ Cardiothorac Vasc Anesth, 2010, 24(2): 306-8.

[86] Trevino RP, Bisera J, Weil MH, Rackow EC, Grundler WG. End-tidal $\mathrm{CO}_{2}$ as a guide to successful cardiopulmonary resuscitation: a preliminary report. Crit Care Med, 1985, 13: 910-1.

[87] Garnett A, Ornato JP, Gonzalez ER, Johnson B. End-tidal carbon dioxide monitoring during cardiopulmonary resuscitation. JAMA, 1987, 257: 512-5.

[88] Falk JL, Rackow EC, Weil MH. End-tidal carbon dioxide concentration during cardiopulmonary resuscitation. NEJM, 1988, 318: 607-11.

[89] Peyton P, Venkatesan Y, Hood S, Junor P, May C. Non-invasive, automated and continuous cardiac output monitoring by pulmonary capnodynamics: Breath by breath comparison with ultrasonic flow probe. Anesthesiology, 2006, 105: 72-80.

[90] Ruskin KJ, Shelley KH. Patent medicine and the "black box". Anesth Analg, 2005, 100(5): 1361-2.

[91] Vidal Melo MF, Leone BJ. Introduction of New Monitors into Clinical Anesthesia. Anesth Analg, 107 (3): 749-50, 2008.

[92] National Institute for Health and Clinical Excellence. Medical technologies guidance MTG3: CardioQ ODM oesophageal doppler monitor. March 2011. http://www.nice. org.uk/MTG3.

[93] Miller TE, Roche AM, Gan TJ. Poor Adoption of Hemodynamic Optimization During Major Surgery: Are We Practicing Substandard Care? Anesth Analg, 2011, 112(6): 1274-6.

[94] Ghosh S, Arthur B, Klein AA. NICE guidance on CardioQ ${ }^{\mathrm{TM}}$ oesophageal Doppler monitoring. Anaesthesia, 2011, 66: 1081-3.

[95] Minto G, Struthers R. Oesophageal Doppler monitoring: costly and supported by weak evidence. Anaesthesia, 2012, 67: 426-7.

[96] Nesbitt IDE, Cosgrove JF. Oesophageal Doppler monitoring: a misguided editorial. Anaesthesia, 2012, 67: 427-8.

[97] Chikhani M, Moppett IK. Editorial: Minimally invasive cardiac output monitoring: what evidence do we need? British Journal of Anaesthesia, 2011, 106 (4): 451-3. 


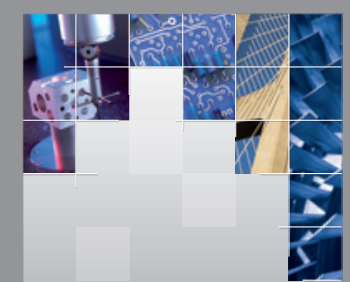

\section{Enfincering}
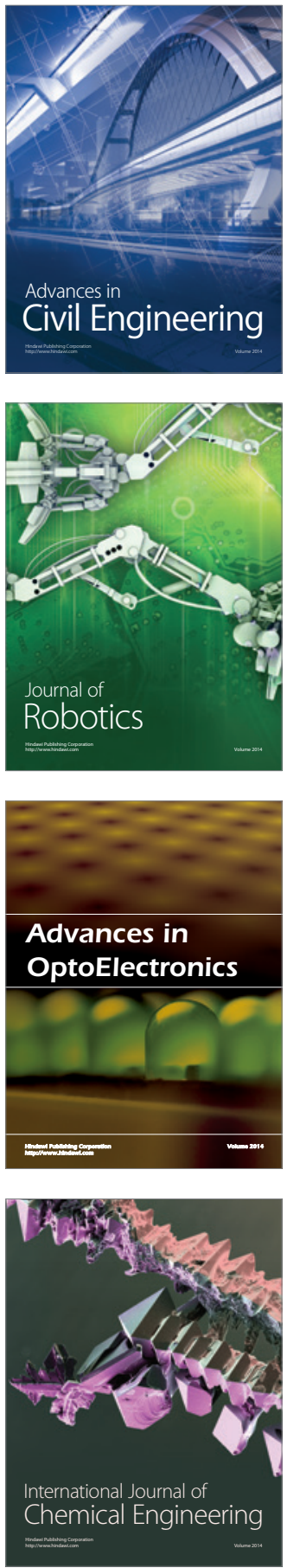

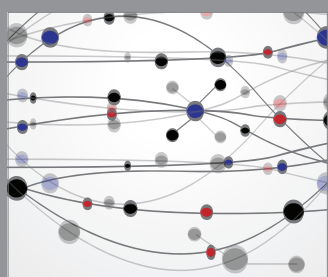

The Scientific World Journal

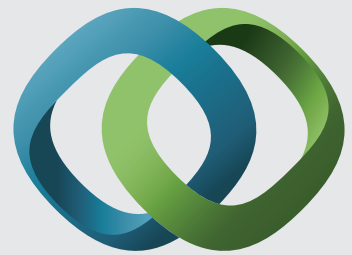

\section{Hindawi}

Submit your manuscripts at

http://www.hindawi.com
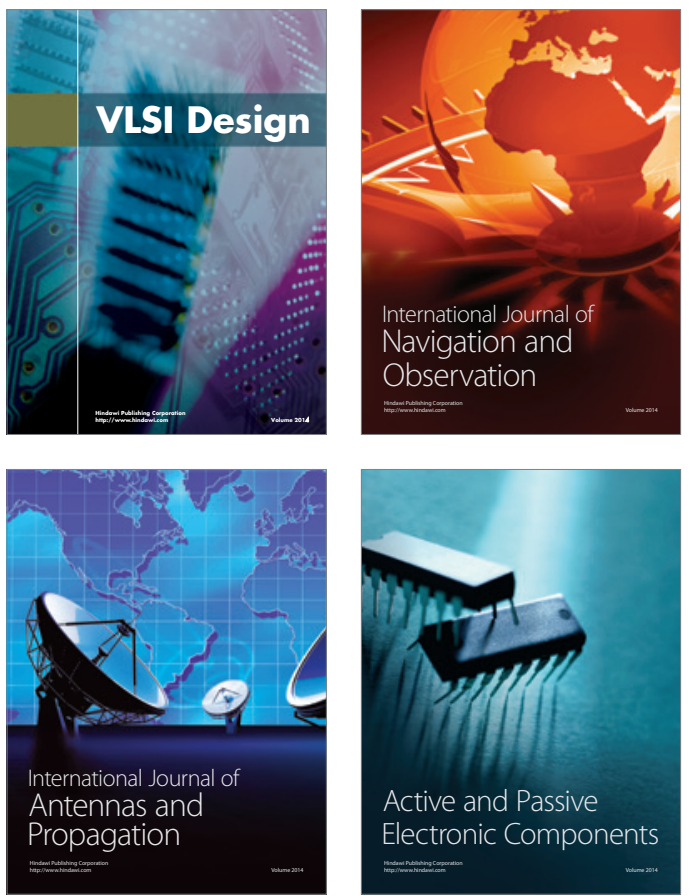
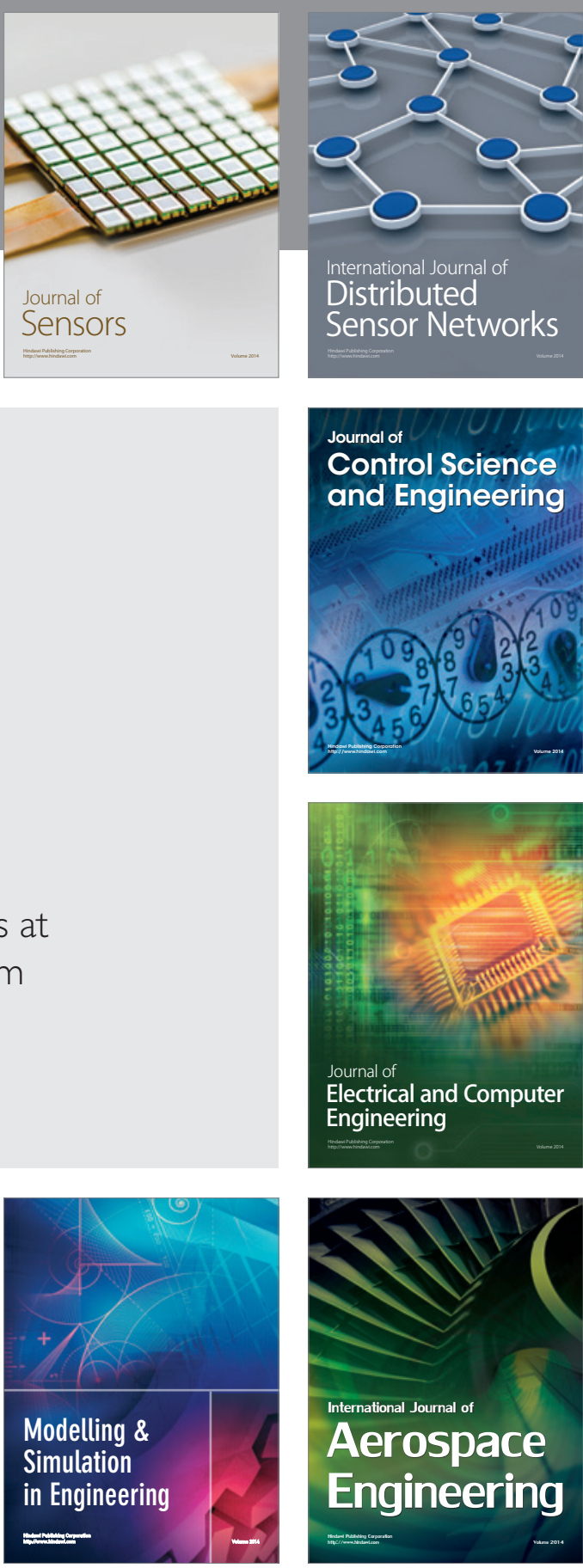

International Journal of

Distributed

Sensor Networks

Journal of

Control Science

and Engineering
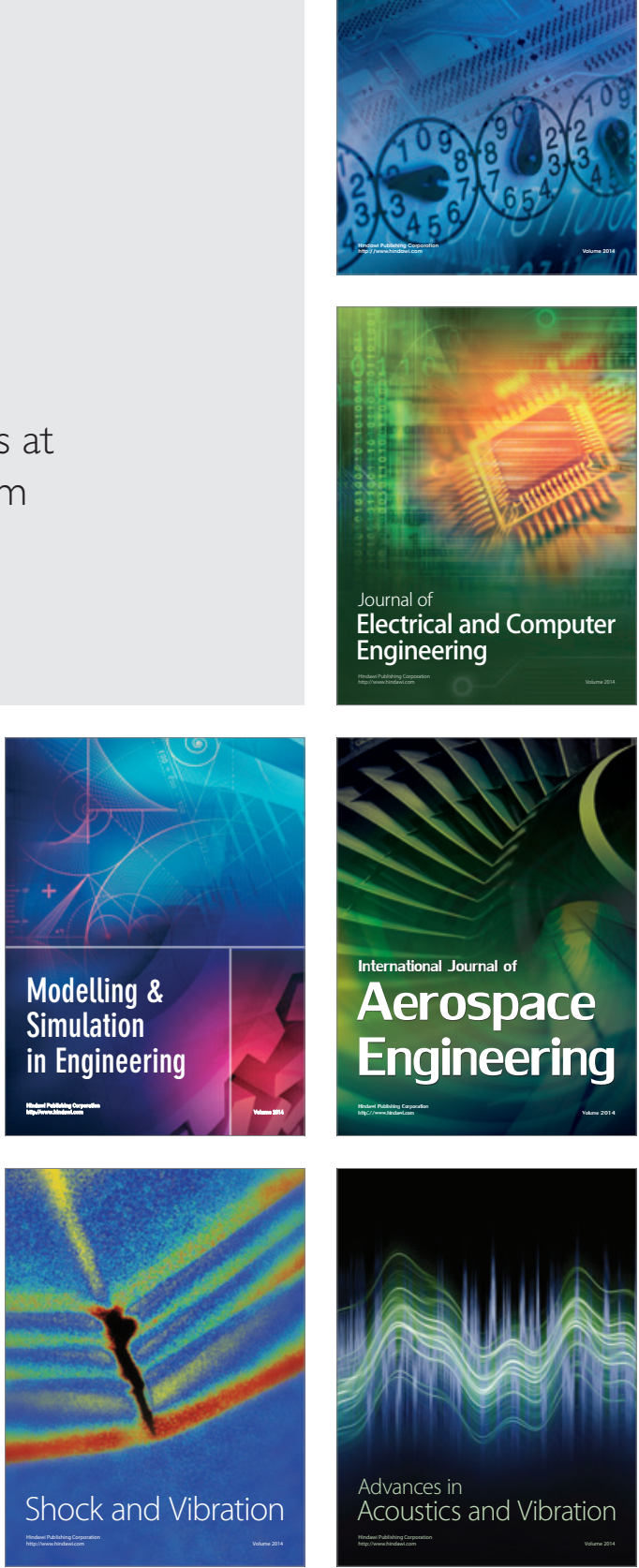